ISSN 2447-9071

doi $10.36414 /$ rbmc.v6i14.34
Contato para correspondência: Leonardo Luiz Borges

E-mail:

leonardo.cbb@pucgoias.edu.br

Conflito de interesse: Não

Financiamento: Recursos próprios

Recebido: $21 / 03 / 2020$

Aprovado: 13/04/2020

\section{Otimização da extração assistida por ultrassom de compostos fenólicos totais e flavonoides a partir dos frutos de acerola (Malpighia sp.)}

\section{Optimization of ultrasound-assisted extraction of total phenolic compounds and flavonoids from acerola fruits (Malpighia sp.)}

\author{
Marques Cardoso ${ }^{1,2}$, Leonardo Luiz Borges ${ }^{1,3}$ \\ 1 Pontifícia Universidade Católica de Goiás - PUC Goiás \\ ${ }^{2}$ Faculdade da Polícia Militar - FPM \\ ${ }^{3}$ Universidade Estadual de Goiás - UEG
}

Blenda Saad Lima da Costa', Janne Lourrany Correia da Costa Vieira', Alessandra

\section{Resumo}

A acerola (Malpighia sp.) éoriginária das Antilhas, pertence à família botânica Malpighiaceae, dentre aos seus constituintes pode-se citar a vitamina C, carotenoides, ácidos fenólicos, furanos, ácido clorogênico, galato de epigalocatequina, epicatequina, procianidina, carboidratos, proteínas, fósforo, cálcio, ferro, riboflavina, fibra, lipídios, tiamina, piridoxina, flavonoides (flavanonas, flavonóis, rutina e antocianinas) e compostos voláteis, os quais podem estar relacionados com suas atividades antifúngica, antibacteriana, antianêmica, adstringente etambém nutricional. Dentre as técnicas de extração de compostos bioativos, destaca-se a extração assistida por ultrassom, por ser uma técnica rápida, de baixo custoeambientalmenteviável.Umaimportanteestratégiapara obtenção demelhores condições de extração para extratos hidroalcóolicos é a otimização que utiliza a metodologia de superfície de resposta (MSR). Neste estudo, utilizou-se o planejamento fatorial Box-Benken para avaliar os possiveis efeitos de tempo, graduação alcoólica (etoh) e proporção sólido: líquido (PSL) sobre a concentração de fenóis totais (FT) eflavonoides (Fv) extraídos daespécieMalpighiasp. Oextratolíquido deMalpighiasp otimizado foi utilizado em testes antimicrobianos pela técnica de difusão em disco adaptada, sendo testado contracepas deStaphylococcus aureus, Klebsiellapneumoniaee Escherichia coli.Os resultados da otimização do extrato de acerola obtiveram-se um r2adj=0,9908 para doseamento de fenóis totais e R2 adj=0,6110 para flavonoides. Em relação aos testes antibacterianos, o extrato líquido de acerola apresentou atividade frente as 3 cepas de bactérias testadas. Obteve-se o extrato de acerola otimizado, o qual apresentou ação antimicrobiana, com isso percebe-se a necessidade de futuros estudos para identificação de quais compostos são responsáveis por desenvolver tal resultado, podendo contribuir com o desenvolvimento farmacêutico.

Palavras-Chave: Box-Behnken, Extrato líquido padronizado, Frutos do cerrado, Atividade antimicrobiana.

\section{Abstract}

Acerola is originally from the Antilles, belonging to the Malpighiaceae botanical family. Vitamin C, carotenoids, phenolics, furans, chlorogenic acid, epigallocatechin gallate, epicatechin, procyanidins, carbohydrates, substances, phosphorus, alcohol, iron include its constituents, riboflavin, fiber, lipids, thiamine, pyridoxine, flavonoids (flavanones, flavonols, rutin, and anthocyanins) and volatile compounds, which may be related to their antifungal, antibacterial, anti-anemic, astringent and also nutritional activities. Among the bioactive compound extraction techniques, including ultrasound-assisted extraction, it is a fast, low cost and environmentally viable technique. An important strategy for the best extraction conditions is the optimization that uses the response surface methodology (RSM). In this 
study, use or plan the Box-Benken factorial to evaluate the possible effects of time, alcoholcontent (etoh) and solid: liquid density (SLD) on the concentration of total phenols (TP) and flavonoids (Fv) extracted from area Malpighia sp. Malpighia sp optimized liquid extract was used in antimicrobial tests by the adapted disc diffusion technique and wastested against Staphylococcus aureus, Klebsiellapneumoniae and Escherichia coli strains. The results of the optimization of the acerola extractor obtain an r2adj= 0.9908 for the complete phenol assay and $R 2$ adj $=0.6110$ for flavonoids. Concerning the antibiotics tested, the acerola liquid extract has activity front as 3 strains of bacteria tested. Therefore, using the optimized acerola extractor or exhibiting antimicrobial action, will realize the need for future studies to identify which are the main components responsible for developing the result, use the investment with pharmaceutical development.

Keywords: Box-Behnken, Standardized liquid extract, Cerrado fruits, Antimicrobian activity.

\section{Introdução}

A acerola (Malpighia sp.) pertence à família botânica Malpighiaceae, é originária das Antilhas, na América Central, e presente também na América do Sul. Devido a sua fácil adaptação em climas tropicais, o Brasil tornou-se um dos maiores exportadores de acerola do mundo', sendo encontrada principalmente na região nordeste, e em menor concentração nas outras regiões do país².

A acerola possui em sua composição substâncias como vitamina C, carotenoides, ácidos fenólicos, furanos, ácido clorogênico, galato de epigalocatequina, epicatequina, procianidina, carboidratos, proteínas, fósforo, cálcio, ferro, riboflavina, fibra, lipídios, tiamina, piridoxina, flavonoides (flavanonas, flavonóis, rutina e antocianinas) e compostos voláteis que fornecem o aroma natural do fruto. Possui importância econômica e pode ser empregado como matériaprima para a produção de geleias, sucos, chás, gomas, polpas e nutracêuticos ${ }^{3.5}$.

Estudos relatam que o estágio de maturação do fruto e a composição do solo em que se encontra a Malpighia sp podem influenciar na constituição do fruto de acerola e consequentemente em suas diversas atividades biológicas como antifúngica, antibacteriana, antianêmica, adstringente e nutricional. Outros efeitos como a atividade quimioproterora, ação contra arteriosclerose, doenças cardiovasculares, doenças neurodegenerativas e também capacidade de retardar o envelhecimento podem ser influenciados com a alteração qualitativa e quantitativa dos metabólitos secundários presentes neste fruto ${ }^{5}$.

A extração de compostos bioativos de espécies vegetais depende de vários fatores, como a técnica empregada, as matérias-primas utilizadas e o tipo de solvente. Dentre as técnicas convencionais, que empregam solventes orgânicos, temperatura e agitação, podemos citar maceração, hidrodes- tilação, infusão, percolação, decocção e extração contínua a quente. Já as técnicas não convencionais as quais demandam maior tecnologia encontra-se extração em contracorrente, extração assistida por microondas, ultrassom, fluido supercrítico e turbólise ${ }^{6,7}$. A extração assistida por ultrassom (US) consiste no emprego de ondas mecânicas de alta frequência ${ }^{8}$. Esse método extrativo ocorre por meio de um fenômeno de cavitação, em que os efeitos causados pelas ondas ultrassônicas criam um ciclo de bolhas e cavidades no líquido solvente que são responsáveis pelo cisalhamento do material vegetal, propiciando a extração de compostos bioativos ${ }^{9,10}$.

As técnicas de otimização de processos, como a metodologia de superfície de resposta (MSR) representam importante estratégia para a obtenção de melhores condições em diversos processos, como em métodos extrativos de metabólitos secundários a partir de espécies vegetais. Essas ferramentas podem ser aplicadas em diversas etapas de obtenção de produtos nas áreas farmacêutica e alimentícia".

Após obtenção de extratos ricos em compostos bioativos, experimentos biológicos podem permitir a investigação de propriedades que beneficiam os seres humanos e/ou animais, sendo a avaliação da atividade antimicrobiana do extrato líquido um caminho a ser pesquisado ${ }^{12}$.

A investigação de novos compostos com atividade antimicrobiana faz-se necessário devido ao aumento de micro-organismos resistentes às substâncias convencionais utilizadas. Diversos ensaios são realizados em plantas medicinais para avaliarem seu potencial antimicrobiano, os quais podemos citar método de difusão em ágar por poço, disco-difusão e métodos de macrodiluição e microdiluição ${ }^{13}$. Tais técnicas auxiliam na descoberta de novas substâncias com propriedades antimicrobianas que podem ser usadas no desenvolvimento de novos produtos eficazes e mais seguras ${ }^{12}$.

$\mathrm{O}$ presente estudo teve como objetivo obter o extrato 
líquido padronizado em compostos fenólicos dos frutos de Malpighia sp. Le avaliar a atividade antimicrobiana do extrato otimizado.

\section{Métodos}

\section{Coleta e processamento}

Os frutos foram coletados no município de Goiânia - GO (16 40'13.1"S 49० 19'22.7"W) e no povoado de Luiz Alves - GO (Latitude-13,2155; Longitude-50, 5779). Após coleta dos frutos lavou-se os mesmos com água corrente e armazenou-se em temperatura - $18^{\circ} \mathrm{C}$. Conforme o necessário retirou-se os frutos congelados para trituração e posterior liofilização.

O processo de liofilização foi realizado em liofilizador LS3000, no qual os frutos triturados de acerola congelados foram colocados em potes de vidros e levados para o liofilizador por sete dias. Após esse período, retirou-se os potes, os mesmos foram lacrados e armazenados em freezer.

\section{Análises quantitativas}

Os experimentos executados em cada etapa das análises foram realizados em duplicatas para confirmação dos resultados.

\section{Doseamento de fenóis totais (FT)}

A determinação do teor de fenóis totais foi realizada de acordo com o método de Hagerman e Buttler adaptado ${ }^{14}$.

Para o processo extrativo de fenóis totais nas amostras, pesaram-se as massas de 0,375, 0,5 e 0,625 g do material vegetal pulverizado dos frutos liofilizados de acerola e transferiuse para um balão de fundo chato de $50 \mathrm{~mL}$ e completou com solução hidroalcóolica (60, 70 e $80 \%$ ). A amostra foi obtida por extração assistida por ultrassom (25, 30 e 35 minutos). A solução foi filtrada em papel de filtro.

Adicionou-se em um tubo de ensaio, $2 \mathrm{~mL}$ de solução de Lauril Sulfato de Sódio/Trietanolamina (LSS), $1 \mathrm{~mL}$ de solução cromogênica de Cloreto férrico ( $\mathrm{FeCl} 3$ ) e $1 \mathrm{~mL}$ da amostra de extrato previamente filtrada. Após $15 \mathrm{~min}$ realizou-se a leitura em espectrofotômetro a $510 \mathrm{~nm}$. Preparou-se o branco com $2 \mathrm{~mL}$ de solução de Lauril Sulfato de Sódio/Trietanolamina, $1 \mathrm{~mL}$ de solução cromogênica de cloreto férrico e $1 \mathrm{~mL}$ de água destilada.

Para a construção da curva padrão pesou-se $100 \mathrm{mg}$ de ácido tânico, transferindo-o para um balão volumétrico de $100 \mathrm{~mL}$, completando-se o volume com $40 \mathrm{~mL}$ de metanol $50 \%$ e o restante com água destilada. Pipetou-se alíquotas de 0,1-0,2-0,3-0,4 e 0,5 mL da solução padrão, transferiuas para tubos de ensaio contendo $2 \mathrm{~mL}$ de solução de LSS/ Trietanolamina e $1 \mathrm{~mL}$ de solução cromogênica de $\mathrm{FeCl}$.
Completou-se o volume para 4,0 mL com água destilada e os tubos foram deixados em repouso por $15 \mathrm{~min}$ antes de realizar a leitura em espectrofotômetro a $510 \mathrm{~nm}$. Construiu-se a curva de calibração padrão (Absorbância x Concentração) de acordo com os dados obtidos.

Para calcular a porcentagem de fenóis totais presentes nas amostras analisadas utilizou-se as seguintes fórmulas:

$$
C=\frac{\text { Absorbância }-A}{B}
$$

$$
\begin{gathered}
\text { \%Fenóis totais }=\mathrm{c} \times \underline{250} \times 10-3 \times 100 \\
\mathrm{~m}(\mathrm{~g})
\end{gathered}
$$

Em que:

$\mathrm{C}$ = concentração de ácido tânico em $\mathrm{mg} / \mathrm{mL}$

$A=$ coeficiente linear da equação da reta

$B=$ coeficiente angular da equação da reta

\section{Doseamento de flavonoides}

A determinação dos teores de flavonoides totais como equivalentes de rutina foi realizada segundo o método descrito modificado. Para extração dos flavonoides, pesou-se 0,375, 0,5 e $0,625 \mathrm{~g}$ da amostra, transferiu-se para um balão de fundo chato de $50 \mathrm{~mL}$ e completou com solução hidroalcóolica (60, 70 e $80 \%)$. Colocou-se em ultrassom (25, 30 e 35 minutos) e posteriormente filtrou-se em papel filtro ${ }^{15}$.

Pipetou-se $3 \mathrm{~mL}$ do filtrado em um tubo de ensaio e realizou-se leitura direta em espectrofotômetro a $361 \mathrm{~nm}$, utilizando-se como branco, solução hidroalcóolica 70\%. Essas leituras foram realizadas em triplicatas.

Para a construção da curva padrão, preparou-se uma solução de rutina a $100 \mu \mathrm{g} / \mathrm{mL}$ em metanol:ácido acético 0,02 M (99:1). Os pontos feitos foram de 10 a $30 \mu \mathrm{g} / \mathrm{mL}$, de forma que pipetou-se alíquotas de 0,2-0,3-0,4-0,5 e 0,6 mL da solução padrão e completou-se com a mistura de metanol: ácido acético 0,02 M (99:1) para $2 \mathrm{~mL}$ num tubo de ensaio. Realizou-se a homogeneização, fez-se a leitura em espectrofotômetro a $361 \mathrm{~nm}$ e construiu-se a curva de calibração padrão (Absorbância $x$ Concentração).

Para calcular a porcentagem de flavonoides presentes nas amostras utilizou-se as seguintes fórmulas:

$$
C=\frac{\text { Absorbância }-A}{B}
$$

\%Flavonoides $=\mathrm{C} \times \underline{500} \times 10-3 \times 100$ $\mathrm{m}(\mathrm{g})$ 
Em que:

$C=$ concentração de rutina em $\mathrm{mg} / \mathrm{mL}$

$A=$ coeficiente linear da equação da reta

$B=$ coeficiente angular da equação da reta

\section{Planejamento fatorial aplicado ao processo extrativo de} fenóis totais e flavonoides a partir dos frutos de Malpighia sp.

O processo de otimização do método extrativo por ultrassom foi conduzido por meio de um planejamento experimental BoxBehnken com 3 fatores sendo três pontos centrais (15 experimentos). Foram avaliadas a influência do tempo de extração- $\mathrm{X} 1$ (min), proporção sólido/solvente - X2 ( $\mathrm{g} / 50 \mathrm{~mL})$ e teor alcoólico - X3 (\% $\mathrm{v} / \mathrm{v}$ ), na quantificação de fenóis totais e flavonoides.

Tabela 1. Fatores e respectivos níveis utilizados no processo de otimização da extração assistida por ultrassom do material liofilizado dos frutos de Malphigia sp.

\begin{tabular}{ccc}
\hline & Nível 1 & \\
\hline Fator & $\mathbf{- 1}$ & $\mathbf{1}$ \\
Tempo(min) & 25 & 35 \\
PSL (g/50 ml) & 0,375 & 0,625 \\
EtOH (\%) & 60 & 80 \\
\hline
\end{tabular}

Legenda: PSL: proporção sólido líquido; EtOH: etanol.

\section{Análise antibacteriana do extrato líquido obtido de $\mathbf{M a l}$ - pighia sp}

Para a obtenção do extrato líquido concentrado empregado no ensaio de atividade antimicrobiana, a melhor condição do planejamento Box-Behnken foi reproduzida e o extrato concentrado em rotaevaporador a pressão reduzida e em banho de $40^{\circ} \mathrm{C}$.

\section{Preparo do inóculo}

Cepas padrão das bactérias Escherichia coli (ATCC 25923) e Klebsiella pneumoniae (ATCC 700603) foram reativadas em ágar MacConkey, e no ágar manitol sal o Staphylococcus aureus (ATCC 25923), posteriormente foram incubadas por 24 horas, a $37^{\circ} \pm 1^{\circ} \mathrm{C}$. Após crescimento, as colônias bacterianas foram transferidas para solução fisiológica a 0,85\% (p.v) até obter turvação equivalente ao padrão 0,5 da escala de McFarland, que corresponde aproximadamente a 1,5 x $108 \mathrm{UFC} / \mathrm{mL}$. Posteriormente, semeou-se a suspensão bacteriana em placas de Petri em meio ágar Mueller-Hinton, com auxílio de swab.

\section{Teste de Difusão}

A avaliação da atividade antimicrobiana do extrato líquido acerola foi realizada pela técnica da difusão em ágar. Após semeadura da suspensão bacteriana, procedeu-se a abertura de sete orifícios no meio de cultura, com auxílio de um tubo de ensaio estéril $10 \mathrm{~mL}$, formando poços, sendo estes preenchidos com 10, 25, 50, 100, 150, 200 e $300 \mu \mathrm{l}$ do extrato com auxílio de pipetas semiautomáticas.

As placas foram então incubadas em estufa bacteriológica a $37 \pm 1^{\circ} \mathrm{C}$. Transcorrido o tempo de incubação (48 horas), procedeu-se a leitura dos diâmetros dos halos de inibição.

\section{Resultados e Discussão}

A partir dos 15 experimentos executados conforme o planejamento fatorial Box-Behnken, obteve-se os resultados referentes as concentrações de fenóis totais e flavonoides, conforme a Tabela 2.

Tabela 2. Planejamento fatorial realizado em 15 experimentos desenvolvido pelo Box-Behnken para obtenção do extrato líquido dos frutos de acerola e suas respectivas absorbâncias de flavonoides e fenóis totais.

\begin{tabular}{|c|c|c|c|c|}
\hline EtOH (\%) & PSL (g) & Tempo (min) & FT & Fv \\
\hline 60 & 0,5 & 35 & 35 & 35 \\
\hline 35 & 0,283 & 0,088 & 35 & 35 \\
\hline 80 & 0,5 & 35 & 0,284 & 0,108 \\
\hline 70 & 0,375 & 35 & 0,199 & 0,088 \\
\hline 70 & 0,625 & 35 & 0,333 & 0,152 \\
\hline 60 & 0,375 & 30 & 0,192 & 0,063 \\
\hline 80 & 0,375 & 30 & 0,183 & 0,088 \\
\hline 60 & 0,625 & 30 & 0,309 & 0,082 \\
\hline 80 & 0,625 & 30 & 0,301 & 0,135 \\
\hline 70 & 0,5 & 30 & 0,273 & 0,087 \\
\hline 70 & 0,5 & 30 & 0,265 & 0,089 \\
\hline 70 & 0,5 & 30 & 0,262 & 0,08 \\
\hline 60 & 0,5 & 25 & 0,303 & 0,094 \\
\hline 80 & 0,5 & 25 & 0,243 & 0,118 \\
\hline 70 & 0,375 & 25 & 0,211 & 0,092 \\
\hline 70 & 0,625 & 25 & 0,199 & 0,073 \\
\hline
\end{tabular}

Legenda: FT: fenóis totais; FV: flavonoides; PSL:proporção sólido líquido; EtOH: etanol. 
A partir da leitura das absorbâncias dos fenóis totais do extrato líquido, o mesmo deve-se ser analisado. Portanto utiliza-se um software que permite desenvolver um modelo quadrático da extração de fenóis, sendo este a análise de variância (ANOVA).

Tabela 3: Análise de variância (ANOVA) referente ao modelo quadrático da extração de fenóis totais assistida por ultrassom a partir dos frutos liofilzados de acerola.

\begin{tabular}{|c|c|c|c|c|c|}
\hline Fonte & $\begin{array}{l}\text { Soma de } \\
\text { quadrados }\end{array}$ & gl & $\mathbf{F}$ & Prob $>$ F & $\mathbf{p}$ \\
\hline Modelo & 0,033 & 11 & 2,996E-003 & 137,40 & 0,0009 \\
\hline A-EtOH & 8,619E-004 & 1 & 8,619E-004 & 39,52 & 0,0081 \\
\hline B-PSL & $3,721 \mathrm{E}-003$ & 1 & $3,721 \mathrm{E}-003$ & 170,63 & 0,0010 \\
\hline C-Tempo & $3,721 \mathrm{E}-003$ & 1 & $3,721 \mathrm{E}-003$ & 170,63 & 0,0010 \\
\hline$A B$ & $2,500 \mathrm{E}-007$ & 1 & 2,500E-007 & 0,011 & 0,9215 \\
\hline$A C$ & 9,389E-004 & 1 & $9,389 \mathrm{E}-004$ & 43,06 & 0,0072 \\
\hline$B C$ & 5,329E-003 & 1 & 5,329E-003 & 244,37 & 0,0006 \\
\hline$A^{2}$ & $4,632 \mathrm{E}-004$ & 1 & 4,632E-004 & 21,24 & 0,0192 \\
\hline $\mathrm{B}^{2}$ & $3,722 \mathrm{E}-003$ & 1 & $3,722 \mathrm{E}-003$ & 170,66 & 0,0010 \\
\hline$A^{2} B$ & 1,596E-003 & 1 & 1,596E-003 & 73,19 & 0,0034 \\
\hline$A^{2} C$ & $1,268 \mathrm{E}-003$ & 1 & $1,268 \mathrm{E}-003$ & 58,14 & 0,0047 \\
\hline$A B^{2}$ & $2,175 \mathrm{E}-004$ & 1 & $2,175 \mathrm{E}-004$ & 9,98 & 0,0509 \\
\hline Resíduo & $6,542 \mathrm{E}-005$ & 3 & 2,181E-005 & & \\
\hline Falta de ajuste & 7,549E-007 & 1 & 7,549E-007 & 0,023 & 0,8926 \\
\hline Erro puro & 6,467E-005 & 2 & 3,233E-005 & & \\
\hline Cor total & 0,033 & 14 & & & \\
\hline
\end{tabular}

Legenda: gl: grau de liberdade; FV: flavonoides; PSL:proporção sólido líquido; EtOH: etanol.

Pode-se observar a partir da Tabela 3, que o modelo obtido para FT foi significativo $(p=0,009)$, apresentou falta de ajuste não significativo $(p=0,8926)$. Além disso, o valor de R2adj $=0,9908$ revela que o modelo em questão consegue explicar 99,08\% do comportamento extrativo dos dados de fenóis totais em função dos fatores Tempo, PSL e EtOH. Assim, a partir da análise de variância (ANOVA) deste modelo, é possível considerá-lo adequado para a predição das melhores condições de extração dentro dos níveis avaliados.

A ANOVA gera uma equação que possui todas as variáveis possíveis demonstrada pelo modelo quadrático, pois através desta equação, pode-se calcular quando houver condições de extrações diferentes desse experimento. A seguir, tem-se a equação 1 para o modelo de análise de fenóis totais.

Equação 1:
$F T=+0.27-0.015 \times A+0.030 \times B+0.031 \times C+2.500 E-004 \times A \times B$ $+0.015 \times A \times C+0.036 \times B \times C+0.011 \times A^{2}-0.032 \times B^{2}+0.028 \times A^{2} \times$ $B-0.025 \times A^{2} \times C+0.010 \times A \times B^{2}$

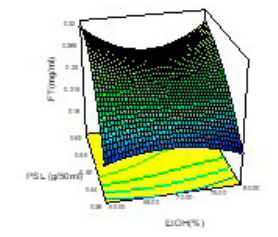

A

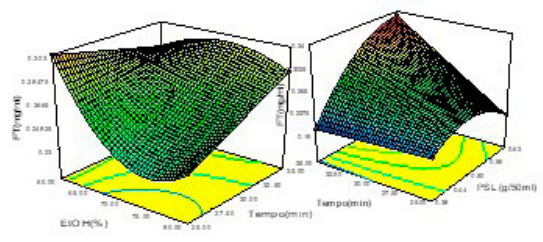

B

$\mathrm{C}$

Figura 1. Gráficos de superfície de resposta representando a variação de FT em função de PSL e EtOH (A); EtOH e Tempo (B) e Tempo e PSL (C).

Legenda: FT: fenóis totais; PSL: proporção sólido líquido; EtOH: etanol.

A partir da Equação 1, obteve-se o gráficos de superfície de resposta, representados na Figura 1. A melhor condição extrativa de fenóis totais ocorreu nas condições que se teve proporção sólido líquido (PSL) aproximadamente de 0,63 $\mathrm{g} / 50 \mathrm{~mL}$ e EtOH $60 \%$ obtendo-se uma concentração de FT de aproximadamente $0,32 \mathrm{mg} / \mathrm{mL}$ (figura $1 \mathrm{~A}$ ). Na Figura 1B, pode-se obervar que a graduação álcoolica e tempo de extração responsáveis pelas maiores concentrações de FT $(0,303$ $\mathrm{mg} / \mathrm{ml}$ ), foram $60 \%$ e $25 \mathrm{~min}$ respectivamente. Já a figura $1 \mathrm{C}$ as variáveis consideradas foram tempo ( $\mathrm{min}$ ) e PSL (g/50mL), em que o tempo foi $35 \mathrm{~min}$ e PSL 0,63 g/50mL. Estas condições levaram a extrair $0,34 \mathrm{mg} / \mathrm{mL}$ de $\mathrm{FT}$.

O método assistido por ultrassom para extrair compostos fenólicos de resíduos de alcachofra, no qual obtiveram maiores rendimentos dos compostos fenólicos, comprovando a eficácia da técnica de extração ${ }^{16}$.

O ultrassom para extrair polissacarídeos com atividade antioxidante das frutas de amoreira preta, de acordo esses estudos obtiveram rendimento máximo de 3,13\%, mostrando que a técnica de ultrassom desempenhou uma extração eficaz ${ }^{17}$.

A extração assistida por ultrassom atualmente vem se destacando como uma excelente técnica para a obtenção de compostos bioativos, pois é possível adquirir elevada concentração dos compostos em estudos, devido método não 
ser destrutível, e capaz de extrair os compostos da amostra, em menor tempo e temperatura, dependendo da análise em questão, além de reduzir o gasto de solventes que muitas técnicas convencionais ocasionam.

A análise de variância (ANOVA) abaixo, foi feita a partir das concentrações do extrato líquido dos frutos de acerola presentes na Tabela 2, semelhante a Tabela 3.

Tabela 4: Análise de variância (ANOVA) referente ao modelo quadrático da extração de flavonoides assistida por ultrassom a partir dos frutos liofilzados de acerola.

\begin{tabular}{lccccc}
\hline Fonte & $\begin{array}{c}\text { Soma de } \\
\text { quadrados }\end{array}$ & gl & $\mathbf{F}$ & Prob $>$ F & p \\
\hline Modelo & $5,558 \mathrm{E}-003$ & 4 & $1,390 \mathrm{E}-003$ & 6,50 & 0,0076 \\
A-EtOH & $1,860 \mathrm{E}-003$ & 1 & $1,860 \mathrm{E}-003$ & 8,70 & 0,0145 \\
B-PSL & $1,540 \mathrm{E}-003$ & 1 & $1,540 \mathrm{E}-003$ & 7,20 & 0,0229 \\
C-Tempo & $4,351 \mathrm{E}-004$ & 1 & $4,351 \mathrm{E}-004$ & 2,03 & 0,1842 \\
BC & $1,722 \mathrm{E}-003$ & 1 & $1,722 \mathrm{E}-003$ & 8,05 & 0,0176 \\
Resíduo & $2,138 \mathrm{E}-003$ & 10 & $2,138 \mathrm{E}-004$ & & \\
Falta de ajuste & $2,094 \mathrm{E}-003$ & 8 & $2,617 \mathrm{E}-004$ & 11,72 & 0,0810 \\
& & & & & \\
Erro puro & $4,467 \mathrm{E}-005$ & 2 & $2,233 \mathrm{E}-005$ & & \\
Cor total & $7,696 \mathrm{E}-003$ & 14 & & & \\
\hline
\end{tabular}

Legenda: FT: fenóis totais; FV: flavonoides; PSL:proporção sólido líquido; EtOH: etanol.

Neste modelo apenas os fatores EtOH, PSL, Tempo e PSL xTempo apresentaram efeito significativo sobre a extração de flavonoides, sendo os $\mathrm{R} 2$ adj $=0,6110$, comparando com o valor de extração de FT, podemos dizer que foi inferior, pois o esperado é próximo de 1 . Porém o $\mathrm{R} 2 \mathrm{adj}=0,6110$ revela que o modelo para flavonoides apresenta uma explicabilidade do sistema de 61,10\%.

Assim como a equação 1 , o mesmo acontece com a equação 2, a qual também é gerada pela ANOVA, e está representada abaixo, com as condições de extração de flavonoides no extrato líquido dos frutos de acerola, as quais podem ser alteradas quando houver necessidade de mudança dos valores das variáveis em questão.

\section{Equação 2:}

$F v=+0.096+0.015 \times A+0.014 \times B+7.375 E-003 \times C+0.021 \times B \times C$

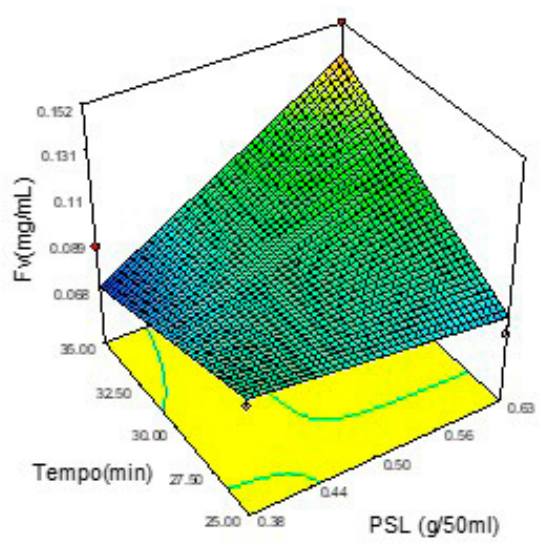

Figura 2: Gráficos de superfície de resposta representando a variação de Fv em função de PSL e Tempo.

Na Figura 2 pode-se observar as melhores condições de extração de FV, sendo o tempo de $35 \mathrm{~min}$ e $0,63 \mathrm{~g} / 50 \mathrm{~mL}$ de PSL, obtendo aproximadamente $0,140 \mathrm{mg} / \mathrm{mL}$ de FV.

Segundo um estudo, o fruto analisado (ameixa) obteve melhores concentrações de flavonoides com extração a temperatura aproximadamente $60^{\circ} \mathrm{C}$. Porém neste estudo o objetivo foi analisar condições intermediárias, que seriam capazes de extrair maiores concentrações de compostos fenolicos e flavonoides, diminuindo o gastos de solventes e otimizando o tempo ${ }^{18}$. Isso pode ser observado através da função de desejabilidade em que se encontrou valor de 1 (valor máximo que se pode obter nessa função), obtendo concentrações de FT $(0,355826 \mathrm{mg} / \mathrm{mL})$ e flavonoides $(0,1520 \mathrm{mg} / \mathrm{mL})$ em tempo de aproximadamente 35 minutos, PSL $0.62 \mathrm{~g} / 50 \mathrm{~mL}$ e solução hidroalcóolica de $80 \%$.

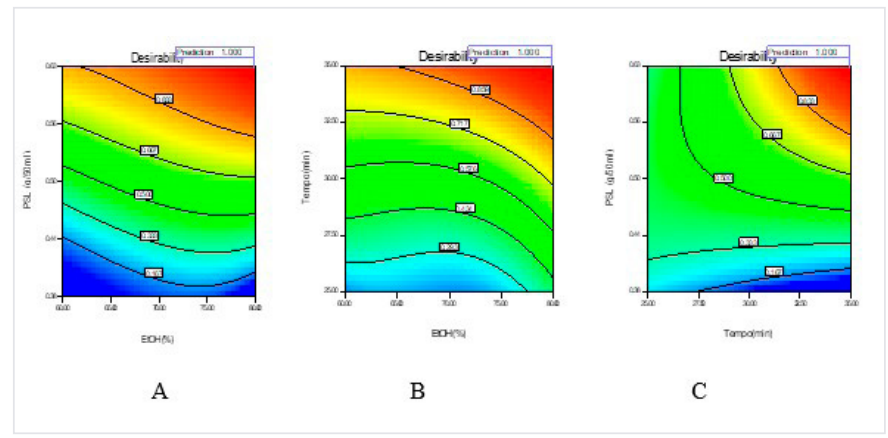

Figura 3: Gráficos obtidos com base na função de desejabilidade demonstrando as melhores condições de PSL, EtOH e tempo para extração de flavonoides e fenóis totais.

Legenda: FT: fenóis totais; FV: flavonoides; PSL:proporção sólido líquido; EtOH: etanol. 
Os gráficos de contorno avaliam a variação da desejabilidade (referente a concentração de FT e Fv) em função dos fatores investigados (tempo, PSL e EtOH).

Em relação a avaliação de desejabilidade em que se tem extração de fenóis totais e flavonoides nas maiores concentrações, considerando as variáveis de tempo, EtOH e PSL obtevese a função de desejabilidade monstrando o melhor de cada fator interferente e a concentração desejável de fenóis totais e flavonoides. Essa relação também pode ser visualizada na figura 3, no qual tem-se a figura $3 \mathrm{~A}$ comparando a variável de PSL e EtOH, sendo que teve-se uma melhor extração com etanol $80 \%$ e PSL de aproximadamente $0,63 \mathrm{~g} / 50 \mathrm{~mL}$. Já a figura $3 \mathrm{~B}$ mostra a relação de tempo e etanol, no qual a melhor extração ocorreu com etanol $80 \%$ e tempo de 35 minutos. $E$ na figura $3 \mathrm{C}$ tem-se a relação da melhor condição entre tempo (35 minutos) e PSL (0,63 g/50 mL).

No intuito de investigar o potencial antimicrobiano do extrato líquido dos frutos de acerola otimizado, realizou-se a avaliação de sua atividade frente a cepas de Escherichia coli (ATCC 25923), Klebsiella pneumoniae (ATCC 700603) e Staphylococcus aureus (ATCC 25923), avaliando a formação de halos de inibição de crescimento bacteriana. A seguir, tem-se a Tabela 5 com as respectivas concentrações de inibidas e diâmetros dos halos de inibição.

Tabela 5: Medidas dos halos de inibição do crescimento bacteriano encontrados na avaliação da atividade antimicrobiana do extrato dos frutos de acerola por meio do método de difusão em disco adaptado.

\begin{tabular}{|c|c|c|c|c|c|c|c|}
\hline Bactérias & $10 \mu \mathrm{l}$ & $25 \mu \mathrm{l}$ & $50 \mu \mathrm{l}$ & $100 \mu \mathrm{l}$ & $150 \mu \mathrm{l}$ & $200 \mu \mathrm{l}$ & $300 \mu \mathrm{l}$ \\
\hline $\begin{array}{l}\text { Staphylococcus } \\
\text { aureus }\end{array}$ & - & - & - & $\begin{array}{c}18 \\
\mathrm{~mm}\end{array}$ & $\begin{array}{c}23 \\
\mathrm{~mm}\end{array}$ & $\begin{array}{c}20 \\
\mathrm{~mm}\end{array}$ & $\begin{array}{c}22 \\
\mathrm{~mm}\end{array}$ \\
\hline $\begin{array}{l}\text { Klebsiella } \\
\text { pneumoniae }\end{array}$ & - & - & - & - & $\begin{array}{c}19 \\
\mathrm{~mm}\end{array}$ & $\begin{array}{c}17 \\
\mathrm{~mm}\end{array}$ & $\begin{array}{c}21 \\
\mathrm{~mm}\end{array}$ \\
\hline Escherichia coli & - & - & - & - & $\begin{array}{c}18 \\
\mathrm{~mm}\end{array}$ & $\begin{array}{c}18 \\
\mathrm{~mm}\end{array}$ & $\begin{array}{c}20 \\
\mathrm{~mm}\end{array}$ \\
\hline
\end{tabular}

Conforme a Tabela 5 verifica-se que os maiores halos formados foram obtidos com os volumes de extrato de $150 \mu \mathrm{l}, 200 \mu \mathrm{l}$ e $300 \mu \mathrm{l}$. Contundo obteve-se inibição com volumes menores do extrato, tendo uma pequena formação de halo. Os testes foram repetidos após uma semana, sendo que o extrato em estudo ficou armazenado em geladeira durante tal período.

O extrato dos frutos de acerola otimizado mostrou-se eficaz ao inibir a bactéria Klebsiella pneumoniae, que de acordo com estudos, a cepa possui uma resistência antimicrobiana vasta, de aproximadamente $95 \%$ dos antimicrobianos encontrados no mercado farmacêutico, esta bactéria possui mecanismos próprios para inibir ação dos antimicrobianos produzindo a enzima beta-lactamases ${ }^{19,20}$.

De acordo com um estudo, E. coli possui resistência aos antimicrobianos variável, em 17 cepas de E. coli testadas pelo autor somente dois antibióticos inibiram as 17 cepas, a Tobramicina (TO) e Gentamicina (GE). O extrato dos frutos de acerola otimizado foi capaz de inibir E. coli (ATCC 25923) em três volumes $150 \mu \mathrm{l}, 200 \mu \mathrm{l}$ e $300 \mu \mathrm{l}$, mostrando alto potencial antibacteriano frente a cepa em estudo ${ }^{21}$.

Por outro lado, um estudo realizado testando extratos brutos de cajueiro, barbatimão, aroeira, favela, fedegoso e quixaba não inibiram o crescimento de Staphylococcus aureus e Escherichia coli ${ }^{22}$. E como observado na tabela 3, o extrato dos frutos de acerola foi capaz de desenvolver atividade frente a esses microrganismos. Com isso, percebe-se a necessidade de outros estudos para analisar os principais compostos do fruto da Malpighia sp que desenvolvem tal atividade, além de testar a otimização do mesmo em outras condições que poderão aumentar a ação antimicrobiana ${ }^{22}$.

Olaleye testou o extrato alcoólico de cálices de Hibiscus sabdariffa $L$. como um agente antibacteriano frente aos micro-organismos Staphylococcus aureus, Bacillus stearothermophilus, Micrococcus luteus, Serratia mascences, Clostridium sporogenes, Escherichia coli, Klebsiella pneumoniae, Bacillus cereus e Pseudomonas fluorescence, tal extrato apresentou atividade antimicrobiana, sendo até mesmo comparado com à ação da estreptomicina, só que o antibiótico não inibe $\mathrm{a} E$. coli ao contrário do extrato de Hibiscus sabdariffa $L^{23}$.

\section{Conclusão}

Os resultados obtidos no processo otimização do extrato líquido da acerola demonstrou que os flavonoides e fenóis presentes no fruto podem ser extraídos em condições semelhantes, obtendo teores significantes. $O$ extrato líquido da acerola otimizado apresentou atividade antibacteriana avaliada pelo método de difusão contra cepas de Klebsiella pneumoniae (ATCC 700603), Staphylococcus aureus (ATCC 25923) e Escherichia coli (ATCC 25923) em diferentes concentrações. Portanto estudos deverão ser desenvolvidos para identificar quais compostos ativos que oferecem ação antimicrobiana ao extrato líquido. Posteriormente estabelecer condições de controle de qualidade para o material vegetal, pois a partir da geração de informações deste extrato líquido, pode-se estabelecer quais aplicações possíveis de desenvolver com extrato líquido do fruto acerola. 


\section{Referências}

1. Firmo WDCA, Menezes VAM, Passos CEDC, Dias CN, Alves LPL, Dias ICL, et al. Contexto histórico, uso popular e concepção científica sobre plantas medicinais. Cad. Pesq. 2011;18(n. ${ }^{\circ}$ esp.): 90-95.

2. Malpighia in Flora do Brasil 2018 em construção. Jardim Botânico do Rio de Janeiro [acesso em 18 out 2018]. Disponível em: http://floradobrasil.jbrj.gov.br/ reflora/floradobrasil/FB596781.

3. Freitas CAS, Maia GA, Costa JMC, Figueiredo RW, Sousa PHM. Acerola: produção, composição, aspectos nutricionais e produtos. R. Bras. Agrociência. 2006;12(4):395-400.

4. Castro ASB. Atividade farmacológica de extratos de abacate (Percea americana miller), acerola (Malpighia emarginata d.c.) e do flavonóide naringina no tratamento da dislipidemia. Minas Gerais. Dissertação [PósGraduação em Bioquímica Agrícola] - Universidade Federal de Viçosa; 2012.

5. Reis IAO, Santos SB, Pereira FDS, Sobral CRS, Freire MG, Freitas LS, et al. Extraction and Recovery of Rutin from Acerola Waste using Alcohol-Salt-Based Aqueous TwoPhase Systems. Sep Sci Technol. 2014;49(5): 656-63.

6. Oliveira VB, Zuchetto M, Oliveira CF, Paula CS, Duarte AFS, Miguel MD, et al. Efeito de diferentes técnicas extrativas no rendimento, atividade antioxidante, doseamentos totais e no perfil por CLAE-DAD de dicksonia sellowiana (presl.). Hook, dicksoniaceae. Rev. Bras. PI. Med. 2016;18(1), Suppl. I:230-239.

7. Soquetta MB, Terra L de M, Bastos CP. Green technologies for the extraction of bioactive compounds in fruits and vegetables. CYTA - J Food. 2018;16(1):400-12.

8. Chemat, F, Khan, MK. Applications of ultrasound in food technology: processing, preservation and extraction. Ultrasonics sonochemistry. 2011;18(4):813-835.

9. Vardanega R, Santos DT, Meireles MA. Intensification of bioactive compounds extraction from medicinal plants using ultrasonic irradiation. Pharmacognosy reviews. 2014; 8(16):88-95.

10. Patist A, Bates D. Ultrasonic innovations in the food industry: From the laboraty to commercial production. Innov Food Sci Emerg Technol. 2008; 9:147-154.

11. De Brito ES, Pinto GAS, Bruno LM, De Azeredo HMC. A metodologia de superfície de resposta (MSR) na otimização de processos biológicos: a determinação dos valores de $\mathrm{pH}$ e temperatura ótimos para a atividade enzimática. VI Reunião Regional Da SBBQ Nordeste. 2002; 1-4.
12. Duarte MCT. Atividade Antimicrobiana de Plantas Medicinais e Aromáticas Utilizadas no Brasil. Revista Multiciência. 2006; (7):1-13.

13. De Bona EAM, Silva Pinto FGS, Fruet TK, Jorge TCM, De Moura AC. Comparação de métodos para avaliação da atividade antimicrobiana e determinação da concentração inibitória mínima (cim) de extratos vegetais aquosos e etanólicos. Arq. Inst. Biol., São Paulo. 2014; 81(3): 218-225.

14. Waterman PG, Mole AS. A critical analysis of techniques for measuring tannins in ecological studies l: techniques for chemically defining tannins. Oecologia. 1987;72:137-147.

15. Rolim A, Maciel COM, KanekoTM, Consiglieri VO, Salgado-Santos IMN, Velasco MVR. Validation assay for total flavonoids, as rutin equivalents, from Trichilia catigua Adr. Juss. (Meliaceae) and Ptychopetalum olacoides Bentham (Olacaceae) Commercial Extract. Journal of AOAC International. 2005;88:1015-1019.

16. Rabelo RS, Machado MT, Martínez J, Hubinger MD. Ultrasound assisted extraction and nanofiltration of phenolic compounds from artichoke solid wastes. Journal of Food Engineering. 2016; 178:170-180.

17. Chen C, You LJ, Abbasi AM, Fu X, Liu RH. Optimization for ultrasound extraction of polysaccharides from mulberry fruits with antioxidant and hyperglycemic activity in vitro. Carbohydrate Polymers. 2015;130:122-132.

18. Ghitescu RE, Volf, L, Carausu C, Bühlmann AM, Gilca IA, Popa VI. Optimization of ultrasound-assisted extraction of polyphenols from spruce wood bark. Ultrason Sonochem. 2015; 22:535-541.

19. Bradford PA. Extended-spectrum beta-lactamases in the 21 st century: characterization, epidemiology, and detection of this important resistance threat. Rev. Clin Microbiol. 2001;14(4):933-951.

20. Spanu T, et. al. Italian ESBL Study Group. Occur rence of extended-spectrum beta - lactamases in members of the family Enterobacteriaceae in Italy: implications for resistance to beta-lactams and other antimicrobial drugs. Antimicrob Agents Chemother. 2002;46(1):196-202.

21. Franco RM, Mantilla SPSM, Gouvêa R, Oliveira LAT. Resistência antimicrobiana de escherichia coli isoladas de carne e dejetos suínos. Acta Veterinaria Brasilica. 2010;4(1):31-36.

22. Eller SCWS, Feitosa VA, Arruda TA, Antunes RMP, Catão RMR. Avaliação antimicrobiana de extratos vegetais e possível interação farmacológica in vitro. Ver. Ciênc. Farm. Básica Apl. 2015;36(1): 131-136.

23. Olaleye MT. Cytotoxicity and antibacterial activity of Methanolic extract of Hibiscus sabdariffa. J. Med. Plant. Res. 2007;1(1):9-13. 